\title{
Design of Water Saving Irrigation System of Agricultural Greenhouse based on Zigbee Technology
}

\author{
Jie Huang \\ College of Mechanical and Electronic Engineering, Hezhou University, Hezhou, China, 542899 \\ huangjie0773@163.com
}

Keywords: Agricultural greenhouse; Irrigation system; Zigbee; GPRS

\begin{abstract}
In order to effectively save irrigation water for agricultural greenhouse, combined with Zigbee wireless communication technology and GPRS technology, a water-saving irrigation system of agricultural greenhouse was studied and designed. In this paper, the principle of the water saving irrigation system, hardware design and software design are described. The system has been tested. The test results show that it can scientifically and reasonably carry out the irrigation of crops in the agricultural greenhouse according to the humidity value of the soil in the greenhouse and the actual demand of crops. It has the advantages of good water saving effect and convenient operation. It has good application prospects.
\end{abstract}

\section{Introduction}

China is a big agricultural country. Crop irrigation needs to consume a large amount of water ${ }^{[1]}$. Due to the uneven distribution of water resources, there is a great waste of water in agricultural irrigation in the areas with rich water resources. In areas lacking of water resources, it is very important to carry out scientific irrigation for crops ${ }^{[2,3]}$. At same time, it plays a very important role in saving irrigation water and improving the yield of crops. Different crops for water demand are not the same. The same kind of crops in different growth stages of water demand is not the same. According to different crops, it can effectively promote the growth of crops through scientific irrigation $^{[4,5]}$. It can effectively save agricultural irrigation water. On the one hand, the agricultural greenhouse irrigation system usually uses the wired monitoring method. System wiring is not convenient. Extension of the system is not convenient. On the other hand, it usually does not have the function of remote monitoring and control. Administrator needs get to the agricultural greenhouse field to operate the irrigation system. It is not convenient to use. Zigbee is a low cost, low transmission rate, short distance and high reliability of wireless communication technology ${ }^{[6]}$. Zigbee technology has a wide range of applications in forest fire monitoring and precision agriculture.

\section{Structure of the System}

The system consists of monitoring node, control node, router node, coordinator, local monitoring center and remote monitoring center. Its structure is shown in Fig. 1. Zigbee network supports star network structure, tree network structure and network structure ${ }^{[7,8]}$. Tree network structure is adopted in the system. Monitoring node, control node, router node and coordinator set up the network through Zigbee technology. The coordinator and the Local monitoring center are connected through serial port. At the same time, the coordinator and the remote monitoring center are connected through GPRS network. Soil humidity value is monitored by the monitoring node. The control node is used to control the opening and closing of the solenoid valve. Monitoring node transmits the soil humidity value to the coordinator through the Zigbee wireless network. Coordinator sends data to the local monitoring center through the serial port. The data is transmitted to the remote monitoring center through GPRS network. The value of soil humidity in different monitoring area is analyzed and calculated by the humidity center. Crops are irrigated according to the type and growth stage of crops. 


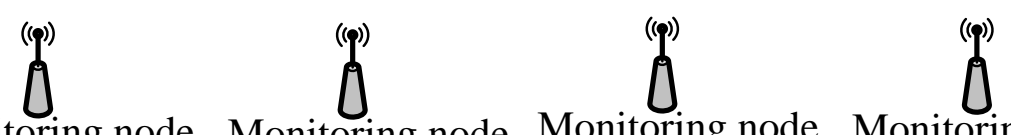

Monitoring node Monitoring node Monitoring node Monitoring node

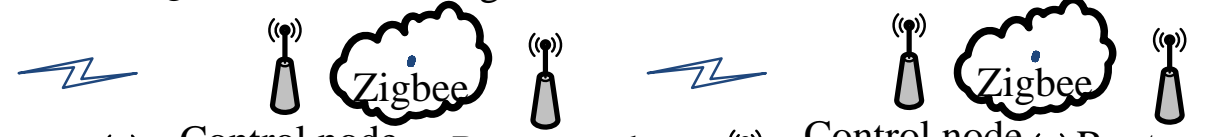

(p) Control node (p) Router node (p) Control node (p) Router node 0 O

Monitoring node Monitoring node Monitoring node Monitoring node

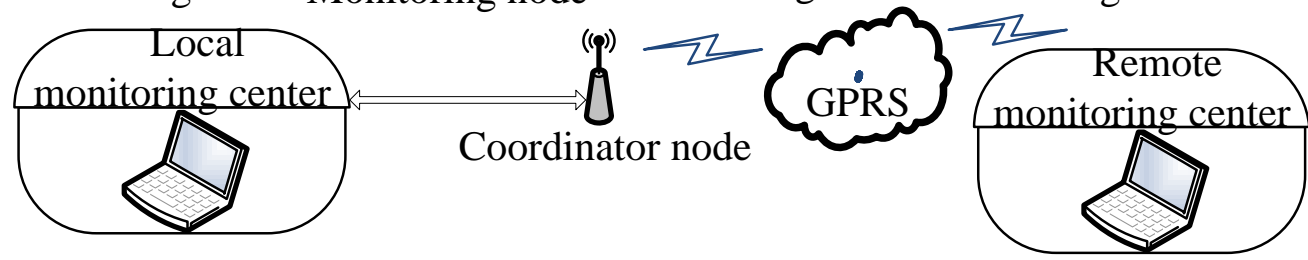

Figure 1. System structure

\section{Hardware Design of the System}

It includes monitoring node hardware design, control node hardware design, router node hardware design and coordinator node hardware design. Monitoring node, control node, router node and coordinator are all using CC2530 chip. Due to the length of the article, the article only describes the hardware structure of the monitoring node and humidity sensor detection circuit.

The monitoring node is composed of a keyboard, multiple humidity sensor modules, a LCD display and an alarm module. Its hardware structure is shown in Fig. 2. In order to accurately collect and measure the humidity of the soil at different depths, the monitoring node can contain multiple humidity sensors according to the actual need of the system. Humidity sensors were used to measure the value of soil humidity at different depths. The type of crops and the growth stage of the crops can be set through the keyboard. The alarm threshold of soil humidity can be set by the keyboard. The soil humidity detection circuit is shown in Fig. 3.

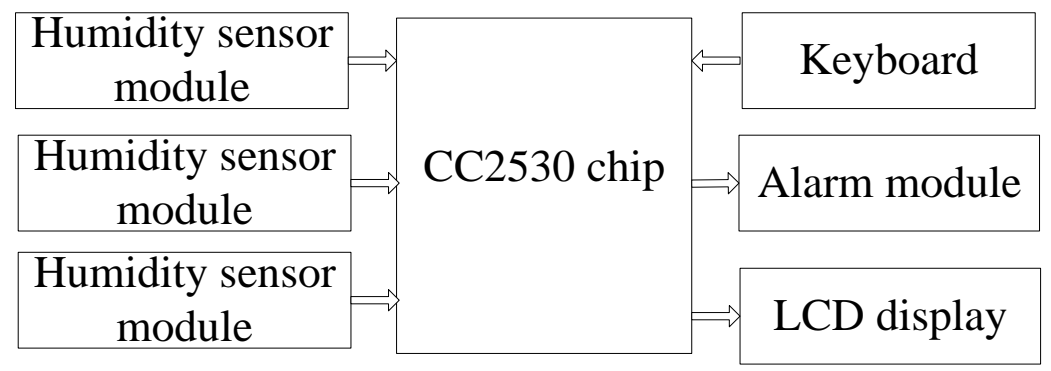

Figure 2. Hardware structure block diagram of monitoring node 


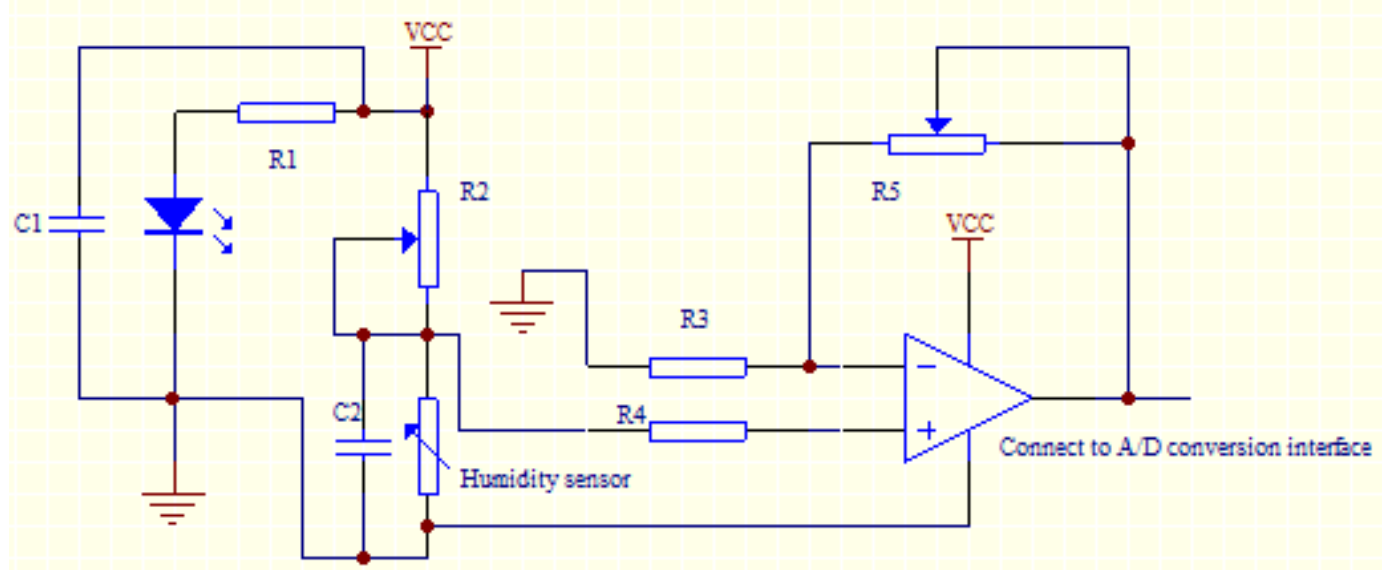

Figure 3. Soil humidity detection circuit

\section{System Software Design}

Functional Design of the System. It has the following functions.

1) It has the function of soil humidity monitoring. The system can monitor the value of soil humidity in each monitoring area of the agricultural greenhouse by monitoring nodes accurately.

2) It has the function of automatic irrigation control. Combined with crop species and the growth stage of crops, according to the value of soil humidity in the agricultural greenhouse, irrigation of crops is automatically controlled by the system.

3 ) It has the function of remote monitoring and control. Administrator can understand and master the monitoring data of the agricultural greenhouse in real time through the monitoring interface of the remote monitoring center. Irrigation of crops can be controlled remotely by monitoring central.

4) It has automatic alarm function. When the system is monitoring the abnormal value of soil humidity in the agricultural greenhouse, it automatically sends out alarm signal. Administrator can take appropriate measures in time according to the alarm signal.

5) The type of crop and the growth stage of the crop can be set by the button of the monitoring node.

Data Fusion Algorithm of the Monitoring Node. Monitoring nodes are deployed in different regions of the agricultural greenhouse. It uses battery power. Monitoring node's energy consumption mainly includes the calculation of energy consumption and communication energy consumption ${ }^{[9]}$. Communication energy consumption accounted for the largest proportion. Reducing the communication energy consumption can effectively reduce the total energy consumption of the monitoring node ${ }^{[10]}$. The humidity data of the monitoring node is processed through the data fusion algorithm. And then decide whether to send data through the Zigbee network. The data fusion algorithm is as follows.

1) Soil humidity value is collected by monitoring node. When the monitoring node collects five soil humidity values, the average value of soil humidity is calculated. The calculated results are saved to the array A. It is assumed that the length of the array is $\mathrm{n}$.

2) It is assumed that the average value of the soil humidity obtained from the last calculation is D. Compare the average value of D with the soil humidity stored in the array.

$$
|D-A[i]|<\varepsilon_{(\mathrm{i}=0,1,2 \ldots, \mathrm{k}-1)}
$$

3) If the Eq.1 is established, then the D is saved to the array A. The value of the $\varepsilon$ can be set according to the accuracy control of the system.

4) If the Eq.1 does not established, the average value of the soil humidity is calculated by the Eq.2. 


$$
\bar{D}=\frac{1}{k+1}\left(D+\sum_{i=0}^{k-1} A[i]\right)
$$

5) $\bar{D}$ is sent through the Zigbee network. The data in the array A is cleared, and the D is saved to the array A.

6) Repeat 2) 5).

Program Design Flow Chart of the Control Center. The monitoring center receives the monitoring data of each monitoring node. Data is analyzed, calculated, updated and stored by the monitoring center. Combined with crop species and the growth stage of crops, according to the value of soil humidity in the agricultural greenhouse, irrigation of crops is automatically controlled by the system. The program design flow of the monitoring center is shown in Fig. 4

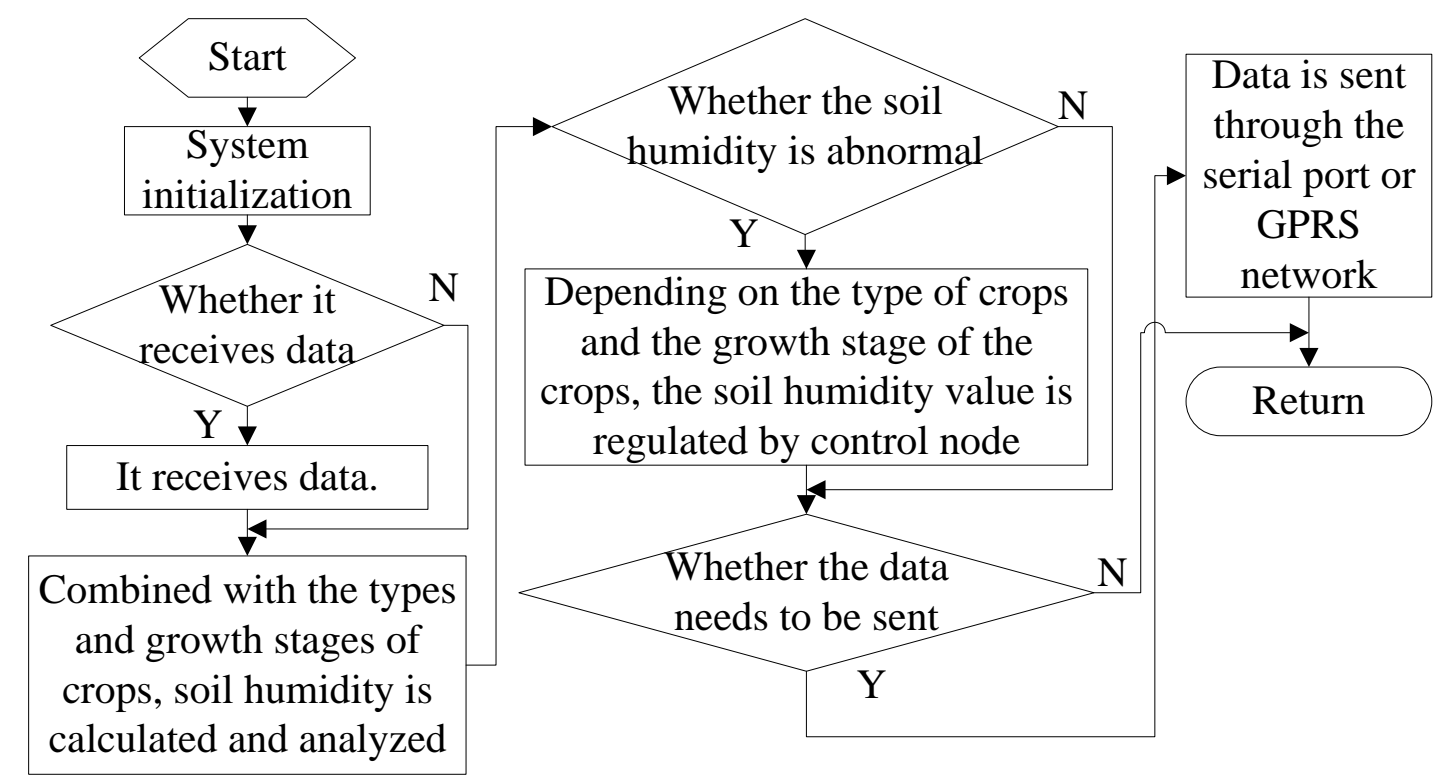

Figure 4. Program design flow chart of the control center

\section{System Test}

The system is installed in an agricultural greenhouse. Twelve monitoring nodes, six control nodes, five router nodes and a coordinator are installed in the appropriate location of the agricultural greenhouse. The coordinator and the local monitoring center are connected through the serial port. The coordinator and the remote monitoring center are connected through the GPRS network. Monitoring node contains three soil humidity sensors. Each soil humidity sensor is installed at different depths of the soil. In the irrigation of crops, it uses intermittent irrigation methods. The system irrigated crops for three minutes. It was stopped for five minutes. Then, according to the value of the soil humidity, it is decided whether to continue the irrigation. The test data of the system are shown in Table 1. The monitoring data in the Table 1 is the measurement data of the system. The measured data in the Table 1 is measured by the instrument. By the test data of the system, the function and performance index of the system meet the design requirements. 
Table 1 System test data

\begin{tabular}{cccccc}
\hline Test item & $\begin{array}{c}\text { Monitoring } \\
\text { data }\end{array}$ & $\begin{array}{c}\text { Measured } \\
\text { data }\end{array}$ & $\begin{array}{c}\text { Relative } \\
\text { error }\end{array}$ & $\begin{array}{c}\text { Threshold of } \\
\text { humidity }\end{array}$ & $\begin{array}{c}\text { Whether to start } \\
\text { irrigation for soil }\end{array}$ \\
\hline & $62.3 \%$ & $63.1 \%$ & $1.2 \%$ & $50 \%$ & No \\
Soil humidity & $53.6 \%$ & $52.7 \%$ & $1.7 \%$ & $50 \%$ & No \\
sensor (1) & $48.5 \%$ & $48.9 \%$ & $0.8 \%$ & $50 \%$ & Yes \\
& $65.7 \%$ & $64.3 \%$ & $2.1 \%$ & $60 \%$ & No \\
Soil humidity & $67.8 \%$ & $68.5 \%$ & $1.0 \%$ & $60 \%$ & No \\
sensor (2) & $57.3 \%$ & $57.6 \%$ & $0.5 \%$ & $60 \%$ & Yes \\
& $52.9 \%$ & $52.3 \%$ & $1.1 \%$ & $45 \%$ & No \\
Soil humidity & $43.6 \%$ & $43.1 \%$ & $1.1 \%$ & $45 \%$ & Yes \\
sensor (3) & $55.7 \%$ & $55.1 \%$ & $1.0 \%$ & $45 \%$ & No \\
\hline
\end{tabular}

\section{Conclusions}

In order to effectively save irrigation water for agricultural greenhouse, combined with Zigbee wireless communication technology and GPRS technology, an agricultural greenhouse water-saving irrigation system was studied and designed. The value of soil humidity in the agricultural greenhouse can be monitored accurately by the system. According to the type and growth stage of crops, the system can carry out scientific irrigation for crops. It has the function of remote monitoring. The system has the advantages of convenient operation and good stability. It has good application prospects.

\section{Acknowledgement}

This work was financially supported by the National Natural Science Foundation of China (Grant No. 6154055).

\section{References}

[1] F.P. Wang and P.P. Feng: Jiangsu Agricultural Sciences, Vol. 42 (2014) No.12, p.404. (In Chinese)

[2] K.S. Zhang, K.Y. Tian, M. Lv and C. Lv: Journal of Xi'an University of Science Technology, Vol. 35 (2015) No.6, p.805. (In Chinese)

[3] W.Y. Li, J.X. Wang and W. Wang: Modern Electronics Technique, Vol. 38 (2015) No.12, p.51. (In Chinese)

[4] G.X. Yu, W.X. Wang, J.X. Xie, H.Z. Lu, J.B. Lin and W.F. Mo: Fujian Journal of Agricultural Science, Vol. 31 (2016) No.7, p.770. (In Chinese)

[5] J.X. Xie, W.X. Wang, H.Z. Lu, X.H. Xu, D. Lin and G.X. Yu: Journal of Irrigation and Drainage, Vol. 33 (2014) No.5, p.189. (In Chinese)

[6] X.Q. Wang, Y.J. Ou and N.L. Huang: Design and Implementation of ZigBee Wireless Sensor Network (Chemical Industry Press, Chinese 2012), p.92. (In Chinese)

[7] L.M. Sun, J.Z. Li, Y. Chen and H.S. Zhu: Wireless Sensor Network (Tsinghua University press, Chinese 2005), p.85. (In Chinese)

[8] H.B. Yu, W. Liang and P. Zeng: Intelligent Wireless Sensor Network System (Science Press, Chinese 2013), P.36. (In Chinese)

[9] P.J. Hu, T. Jiang and Y.D. Zhao: Transactions of the Chinese Society of Agricultural Engineering, Vol. 27 (2011) No.4, p.230. (In Chinese)

[10]H.B. Li, X.F. Xiao, C. Fu and C.Z. Liu: Journal of Drainage and Irrigation Machinery Engineering, Vol. 34 (2016) No.1, p.86. (In Chinese) 